\title{
PENGARUH TRANSFORMATIONAL LEADERSHIP, IKLIM ORGANISASI, STRES KERJA, TERHADAP KOMPETENSI MOTIVASI KERJADAN KINERJAGURU SMP NEGERI DI PROVINSI SULAWESI BARAT
}

\author{
Hasanuddin Lauda*, I.A.Brahmasari², Amiartuti Kusmaningtyas ${ }^{3}$
}

\begin{abstract}
The aim of this study was to analyze the effect of work stress, motivation, and competence of teachers, the performance of teachers in the province of West Sulawesi.The population in this study was the teacher of junior high school has been accredited by the Ministry of Education, with the criteria professorship at least 5 years, Minimum educational backgrounds S-1 and certified. They are a total of 269 junior high school teachers in four districts in West Sulawesi province, while samples taken by Slovin formula and the result was 161 respondents. This study used a questionnaire as the main instrument. And a questionnaire in the form of a modified Likert scale with response options from Agree to Strongly Agree. The data collected is processed by SEM (Structural Equation Modelling) technique with AMOS program version 19. These results indicate that the motivation and competence of junior high school teachers in West Sulawesi get high rankings in the category, and people could improve their performance. While the hypothesis testing results prove that: (1) Work stress a significant effect on the competence of teachers; (2) work motivation significant effect on the competence of teachers; (3) Stress significant effect on teacher performance; (4) Motivation significant effect on teacher performance; and (5) Competence of teachers significantly influence the performance of teachers. Thus, it means that the results of this study prove that all of this hypothesis is accepted.
\end{abstract}

Keywords : Job Stress, Motivation, Competence, and Performance

*) Guru SMK PP Negeri Rea Timur

E-mail: hasanuddin.lauda@yahoo.com 


\section{PENDAHULUAN}

Sekolah merupakan salah satu lembaga pelayanan pendidikan yang memiliki visi, misi, tujuan dan fungsi. Mewujudkan visi, misi, tujuan, dan fungsinya, sekolah memerlukan tenaga yang profesional. Sekolah sebagai suatu sistem memiliki beberapa komponen yang berkaitan satu sama lain serta berkontribusi dalam pencapaian tujuan. Berdasarkan pengamatan dan wawancara singkat dengan beberapa kepala Sekolah SMP Negeri yang ada di Provinsi Sulawesi Barat, pada tanggal 12 Agustus 2014 mengungkapkan bahwa; kinerja guru di sekolahnya belum berkualitas dan profesional jika diukur dari indikator pencapaian kinerja guru yang telah ditetapkan oleh pemerintah. Hal ini berdampak pada belum berkualitasnya proses pembelajaran yang dilaksanakan guru di beberapa SMP Negeri yang ada di Provinsi Sulawesi Barat.

Secara spesifik hasil survei awal tersebut juga menunjukkan bahwa masih kurangnya SMP Negeri yang terakreditasi "A" di Provinsi Sulawesi Barat dari jumlah keseluruhan SMP Negeri sebanyak 331 hanya 8 SMP Negeri yang terakreditasi " $A$ " dan lebih jelasnya dapat dilihat pada Tabel 1 .

Tabel 1. SMP Negeri yang Terakreditasi A di Provinsi Sulawesi Barat

\begin{tabular}{|c|l|c|c|}
\hline No & \multicolumn{1}{|c|}{ Nama Kabupaten } & Jumlah SMP & Akreditasi “A" \\
\hline 1 & Polewali Mandar & 86 & 4 \\
\hline 2 & Majene & 37 & 2 \\
\hline 3 & Mamuju & 71 & 1 \\
\hline 4 & Mamuju Tengah & 28 & - \\
\hline 5 & Mamuju Utara & 44 & - \\
\hline 6 & Mamasa & 65 & 8 \\
\hline
\end{tabular}


Sumber : Dinas Pendidikan Provinsi Sulawesi Barat (2014)

Berdasarkan data yang diperoleh dari Dinas Pendidikan Provinsi Sulawesi Barat yang telah diuraikan pada tabel 1.1. dapat dilihat bahwa dari 331 SMP Negeri yang terbagi ke dalam 6 kabupaten di Provinsi Sulawesi Barat hanya 8 SMP Negeri yang terakreditasi "A" dan tidak semua kabupaten memiliki SMP Negeri yang telah terakreditasi "A". Jika dilihat pada tabel tersebut hanya 4 kabupaten yang memiliki SMP Negeri yang terakreditasi "A" diantaranya; Kabupaten Polewali Mandar, Kabupaten Majene, Kabupaten Mamuju, dan kabupaten Mamasa sedangkan pada kabupaten Mamuju Tengah dan Mamuju Utara tidak satupun SMP Negeri yang memperoleh akreditasi "A" di Kabupaten tersebut. Hal ini menandakan bahwa kinerja guru di sebagian besar SMP Negeri di Provinsi Sulawesi Barat belum maksimal.

Faktor penting yang dapat memengaruhi kinerja guru adalah stres kerja, dan motivasi kerja kompetensi guru. Hal inilah yang membuat peneliti ingin mengkaji lebih mendalam sehingga peneliti mengangkat judul "Pengaruh Stres Kerja, motivasi kerja, dan kompetensi guru, terhadap kinerja guru SMP Negeri di Provinsi Sulawesi Barat"

Masalah penelitian ini adalah apakah stress kerja, motivasi kerja berpengaruh terhadap kompetensi dan kinerja guru SMP Negeri di Provinsi Sulawesi Barat?

Stres biasanya dianggap sebagai suatu yang negatif. Sering dikira disebabkan oleh sesuatu yang buruk misalnya, seorang mahasiswa yang ditempatkan di bagian percobaan, seseorang yang dicintai menderita sakit atau atasan yang memberikan perintah formal karena kinerja yang buruk. Contoh ini adalah sebuah bentuk distress. Menurut Luthans (Muchlas, 2008: 494) stres dapat dipandang dari berbagai cara yang berbeda dan merupakan istilah yang paling sulit didefinisikan dengan tepat.

Menurut Robbins (Muchlas, 2008: 495-496), stres didefinisikan sebagai kondisi yang dinamis di mana seseorang dikonfrontasikan dengan kesempatan, hambatan, atau tuntutan yang berhubungan dengan apa yang diinginkannya dan untuk itu keberhasilannya yang dianggap penting ternyata tidak pasti. Muchlas, (2008: 496) ada dua kondisi penting untuk membuat potensi stres menjadi stres actual.Harus ada ketidakpastian terhadap hasil yang diinginkan dan hasil ini harus 
dianggap penting. Tanpa memandang kondisi-kondisi ini, hanya kalau ada keraguan atau ketidakpastian apakah kesempatan itu diperoleh, hambatan dapat dipindahkan atau kehilangan dapat dihindari, stres akan terjadi. Jadi, stres akan menjadi tertinggi untuk orang-orang yang mempersepsikan bahwa mereka tidak pasti apakah akan menang atau kalah, dan menjadi terendah untuk orang-orang yang berpikir bahwa menang atau kalah itu sudah merupakan suatu kepastian. Tetapi, jika yang dimenangkan atau dikalahkan itu sesuatu hasil yang tidak penting, tidak aka nada stres.Jika mempertahankan pekerjaan atau mengusahakan promosi itu tidak begitu dianggap penting oleh Anda, Anda tidak memiliki alasan untuk merasa stres pada saat menghadapi tinjauan kinerja dari atasan

Isbandi R (dalam Uno, 2006:3) motivasi berasal dari kata motif yang dapat diartikan sebagai kekuatan yang terdapat dalam diri individu, yang menyebabkan individu tersebut bertindak atau berbuat. Hal ini sejalan dengan Hasibuan (2003:95) yang menyatakan bahwa motivasi berasal dari kata dasar motiv, yang mempunyai arti suatu perangsang, keinginan dan daya penggerak kemauan bekerja seseorang. Motivasi adalah pemberian daya penggerak yang menciptakan kegairahan kerja seseorang agar mereka mau bekerjasama dengan efektif dan terintegrasi dengan segala daya upayanya untuk mencapai kepuasan. Dari pengertian yang dikemukakan Mc Donald dalam Sardiman, (2012:74) ini mengandung tiga elemen penting diantaranya bahwa motivasi itu mengawali terjadinya perubahan energi pada diri setiap individu manusia. Motivasi di tandai dengan munculnya, rasa/feeling, efeksi seseorang dalam hal ini motivasi relevan dengan persoalan-persoalan kejiwaan, efeksi dan emosi yang dapat menentukan tingkah laku manusia, Motivasi akan di rancang karena adanya tujuan.

Dengan ketiga elemen diatas, maka dapat di katakana bahwa motivasi sebagai suatu yang kompleks. Motivasi akan menyebabkan terjadinya suatu perubahan energi yang ada pada diri manusia. Sehingga akan bergayut dengan persoalan gejala kejiwaan, perasaan dan juga emosi, untuk kemudian bertindak atau melakukan sesuatu. Semua ini didorong karena adanya tujuan, kebutuhan atau keinginan. 
Istilah kompetensi guru mempunyai banyak makna. Mulyasa, (2004:37-38) mendefinisikan kompetensi sebagai pengetahuan, keterampilan dan kemampuan yang dikuasai oleh seseorang yang telah menjadi bagian dari dirinya, sehingga ia dapat melakukan perilakuperilaku kognitif, afektif dan psikomotorik dengan sebaik-baiknya. Broken dan Stone, (dalam Mulyasa, 2008:25) mengemukakan bahwa kompetensi guru sebagai gambaran kualitatif tentang hakikat prilaku guru yang penuh arti. Secara umum dapat diartikan bahwa guru adalah orang yang bertanggung jawab terhadap perkembangan seluruh potensi anak didik, baik potensi kognitif, potensi afektif, maupun potensi psikomotor. Tugas dan tanggung jawab guru sebenarnya bukan hanya disekolah, tetapi bisa dimana saja mereka berada.

Berdasarkan Peraturan Pemerintah (PP) Nomor 18 Tahun 2007 tentang Guru, dinyatakan bahwasanya kompetensi yang harus dimiliki oleh guru meliputi kompetensi pedagogik, kompetensi kepribadian, kompetensi sosial, dan kompetensi profesional yang diperoleh melalui pendidikan profesi. Kompetensi Guru tersebut bersifat menyeluruh dan merupakan satu kesatuan yang satu sama lain saling berhubungan dan saling mendukung. Menurut Gordon (dalam Mulyasa, 2007:38) ada enam aspek atau ranah yang terkandung dalam konsep kompetensi, yaitu sebagai berikut :Pengetahuan (knowledge), Pemahaman (understanding), Kemampuan (skill), Nilai (value), Sikap (attitude) Minat (interest).

Kata kinerja dalam bahasa indonesia adalah terjemahan dari kata dalam Bahasa Inggris "performance" yang berarti (1) pekerjaan; perbuatan, atau (2) penampilan; pertunjukan. Ruki dalam (Supardi, 2013:45) mengemukakan bahwa kata "kinerja" memberikan tiga arti, yaitu: (1) "prestasi" seperti dalam konteks atau kalimat "hagh performance car" atau "mobil yang sangat cepat"; (2) "pertunjukan" seperti dalam konteks atau kalimat "folk dance performance" atau "pertujukan tari-tarian rakyat"; (3) "pelaksanaan tugas" seperti dalam konteks atau kalimat "in performing his/her duties".

Suprihanto dalam (Supardi, 2013:45) mengemukakan bahwa kata kinerja diartikan sebagai prestasi menujukkan sesuatu kegiatan atau perbuatan dan melaksanakan tugas yang telah dibebankan. UndangUndang Republik Indonesi pasal 7 No.14 Tahun 2005 tentang Guru dan 
Dosen dalam (Supardi, 2013:52) mengemukakan bahwa: Profesi guru merupakan bidang pekerjaan khusus yang di laksanakan berdasarkan prinsip-prinsip:

1. Memiliki bakat, minat, panggilan jiwa dan idealime;

2. Memiliki komitmen untuk meningkatkan mutu pendidikan;

3. Memiliki kompotensi yang diperlukan sesuai bidang tugas;

4. Memperoleh penghasilan yang ditentukan sesuai dengan prestasi kerja;

5. Memiliki kesempatan untuk mengembangkan keprofesionalan secara berkelanjutan;

6. Memiliki jaminan perlindungan hukum dalam keterkaitan dalam melaksanakan tugas keprofesionalan;

7. Memiliki organisasi profesi yang mempunyai kewenangan mengatur hal-hal yang dengan tugas keprofesionalan guru

Berdasarkan pendapat-pendapat di atas dapat disimpulkan bahwa kinerja adalah hasil kerja yang telah dicapai oleh seseorang dalam suatu organisasi untuk mencapai tujuan berdasarkan atas standardisasi atau atau ukuran dan waktu yang disesuaikan dengan norma dan etika yang telah ditetapkan.

Kerangka konseptual penelitian yang menggambarkan pengaruh antar variabel dalam penelitian yang disusun menggambarkan pengaruh langsung dan tidak langsung antara variabel : Stres Kerja $\left(\mathrm{X}_{1}\right)$, Motivasi Kerja $\left(\mathrm{X}_{2}\right)$, dan Kompetensi Guru (Z), terhadap Kinerja Guru (Y). Berdasarkan latar belakang, rumusan masalah, tujuan penelitian dan telaah pustaka yang ada maka kerangka konseptual penelitian ini ditunjukkan pada Gambar 1: Kerangka Konsep Penelitian

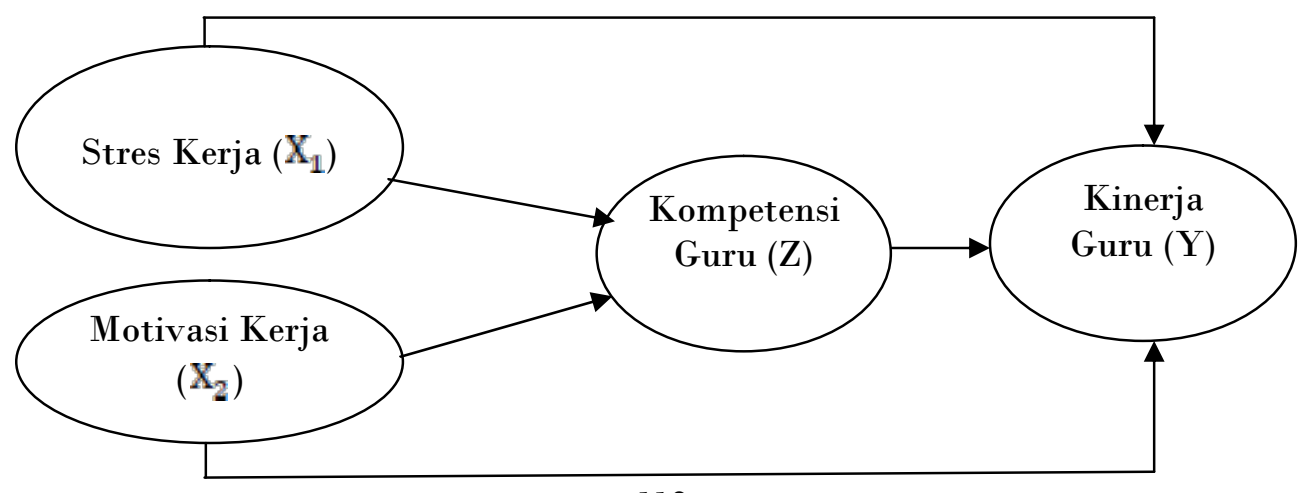


Berdasarkan latar belakang, rumusan masalah dan kerangka konseptual maka hipotesis yang akan diuji dalam penelitian ini dirumuskan :

1. Hipotesis $1\left(\mathrm{H}_{1}\right) \quad$ : Stres kerja berpengaruh signifikan terhadap kompetensi guru SMP Negeri di Provinsi Sulawesi Barat.

2. Hipotesis $2\left(\mathrm{H}_{2}\right)$ : Motivasi kerja berpengaruh signifikan terhadap kompetensi guru SMP Negeri di Provinsi Sulawesi Barat.

3. Hipotesis $3\left(\mathrm{H}_{3}\right) \quad$ : Stres kerja berpengaruh signifikan terhadap kinerja guru SMP Negeri di Provinsi Sulawesi Barat.

4. Hipotesis $4\left(\mathbf{H}_{4}\right)$ : Motivasi kerja berpengaruh signifikan terhadap kinerja guru SMP Negeri di Provinsi Sulawesi Barat.

5. Hipotesis $5\left(\mathbf{H}_{5}\right) \quad$ : Kompetensi guru berpengaruh signifikan terhadap kinerja guru SMP Negeri di Provinsi Sulawesi Barat.

Maka penelitian ini tergolong penelitian explanatory yang bertujuan untuk medapatkan penjelasan dan pemahaman secara empiris tentang bentuk hubungan yang ada antara variabel-variabel penelitian yang telah diuraikan sebelumnya. Populasi dalam penelitian ini adalah Guru-Guru SMP Negeri yang telah terakreditasi A di Provinsi Sulawesi Barat. Jumlah populasi secara keseluruhan dalam penelitian ini adalah 269 orang guru SMP Negeri terakreditasi A di Provinsi Sulawesi Barat yang terbagi dalam 4 Kabupaten.

Teknik pengambilan sampel dalam penelitian ini adalah probabity sampling dimana setiap anggota populasi memiliki kesempatan yang sama untuk dipilih sebagai sampel. Dalam memenuhi hal tersebut maka dalam penelitian ini pengambilan sampel dilakukan secara multi stage dimana tahapan pengambilan sampel dilakukan dengan menentukan terlebih dahulu jumlah sampel yang diambil, baru kemudian mengambil sampel proporsional di setiap kelompok respon dengan menggunakan proporsional random sampling. Pengambilan sampel secara proporsional random 
sampling dilakukan setelah menghitung jumlah sampel dengan rumus Slovin (Riduwan, 2013:65) sebagai berikut :

$$
n=\frac{\mathrm{N}}{N \cdot e^{2}+1}
$$

Di mana : $\quad \mathrm{n}=$ Jumlah Sampel

$\mathrm{N}=$ Total Populasi

$\mathrm{e}^{2}=$ Presisi yang ditetapkan

Sehingga diperoleh sampel sebesar:

$$
\begin{aligned}
& n=\frac{269}{(269) \times\left(0,05^{2}\right)+1} \\
& n=\frac{269}{1.6725}=161
\end{aligned}
$$

Sehingga jumlah total sampel yang diambil sebesar $=161$ responden. Dalam analisis SEM (Structural Equation Modeling) variabel independen disebut variabel eksogen. Variabel independen/eksogen dalam penelitian ada 3 yaitu sebagai berikut:

1. Stres Kerja $\left(\mathrm{X}_{1}\right)$

2. Motivasi Kerja $\left(\mathrm{X}_{2}\right)$

Variabel ini merupakan variabel penyela/antara yang terletak di antara variabel independen dan dependen, sehingga variabel independen tidak langsung memengaruhi berubahnya atau timbulnya variabel dependen (Sugiono, 2013:63). Variabel intervening dalam penelitian adalah Kompetensi Guru (Z). Dalam analisis SEM (Structural Equation Modeling) variabel dependen disebut variabel indogen. Variabel dependen/ indogen dalam penelitian ini adalah; kinerja guru SMP Negeri di Provinsi Sulawesi Barat yang diberi simbol (Y). Guna memperoleh gambaran yang jelas tentang variabel-variabel yang diteliti dalam penelitian ini, maka secara operasional diberikan batasan-batasan agar tidak menimbulkan kesalahan dalam penafsiran variabel penelitian.

Stres kerja guru adalah sesuatu kekuatan dari manusia baik yang bersumber dari dalam organisasi maupun luar organisasi yang 
memberikan tekanan pada diri manusia. Indikator untuk mengukur stres kerja guru diadaptasi dari teori Stephen P. Robbins (2008:375), diantaranya :

1. Psikologis

2. Fisik

3. Prilaku

\section{Motivasi Kerja}

Motivasi merupakan keseluruhan daya penggerak di dalam diri seseorang guru yang diusahakan untuk menimbulkan dan menjamin kelangsungan kerjanya dengan memberikan arah sehingga tujuan kerja yang telah dirumuskan dapat tercapai. Indikator untuk mengukur motivasi kerja guru diadaptasi dari teori Arep \& Tanjung (2004), diantaranya adalah :

1. Bekerja Sesuai Standar

2. Senang Dalam Bekerja

3. Merasa Berharga

4. Bekerja keras

5. Pengawasan

\section{Kompetensi Guru}

Kompetensi guru adalah seperangkat pengetahuan, keterampilan, dan perilaku yang dimiliki, dihayati, dan dikuasai oleh guru yang meliputi kompetensi pedagogik, kompetensi kepribadian, kompetensi sosial dan kompetensi profesional dalam melaksanakan tugasnya. Indikator untuk mengukur kompetensi guru diadaptasi dari undang-undang No.14 tahun 2005 tentang Guru dan Dosen pasal 10 ayat (1) dalam (Mulyasa, 2007:75), diantaranya :

1. Kompetensi Pedagogik

2. Kompetensi Kepribadian

3. Kompetensi Professional

4. Kompetensi Sosial

\section{Kinerja Guru}

Kinerja guru adalah ukuran kuantitatif dan kualitatif yang menggambarkan tingkat pencapaian suatu sasaran atau tujuan yang telah ditetapkan dengan memperhitungkan indikator masukan, proses, dan 
output. Indikator untuk mengukur kinerja guru diadaptasi dari teori (Rusman, 2012:75) diantaranya :

1. Perencanaan guru dalam program kegiatan pembelajaran,

2. Pelaksanaan kegiatan pembelajaran, dan

3. Evaluasi dalam kegiatan pembelajara

\section{METODE PENELITIAN}

Teknik analisis statistik deskriptif yaitu teknik analisis statistik yang digunakan untuk menganalisis data dengan cara mendeskripsikan atau menggambarkan data yang telah terkumpul sebagaimana adanya tanpa bermaksud membuat simpulan yang berlaku untuk umum atau generalisasi (Sugiyono, 2013:169). Analisis deskriptif dimaksudkan untuk mendapatkan gambaran penyebaran hasil penelitian masing-masing variabel secara kategorikal.

Dalam mengukur hubungan antar beberapa variabel seperti pengaruh transformational leadership, iklim organisasi, dan stres kerja, terhadap kompetensi guru, motivasi kerja, dan kinerja guru SMP Negeri di Provinsi Sulawesi Barat sesuai hipotesis yang diformulasikan dan pengujian terhadap hipotesis yang bersangkutan digunakan pemodelan analisis persamaan struktural Structure Equation Modelling (SEM), digunakan karena hubungan diantara variabel-variabel yang diteliti adalah merupakan hubungan kausal yang pengukurannya hanya dapat secara bersama-sama atau serentak agar masing-masing pengaruh dari hubungan yang ada dapat diketahui dengan cepat dan akurat.

Salah satu keunggulan SEM adalah kemampuannya dalam membuat model yang mengandung variabel laten atau variabel-variabel yang tidak diukur (tidak diobservasi) secara langsung. Variabel-variabel laten tersebut diestimasi dalam model melalui variabel-variabel terukur (measured variable) yang diasumsikan mempunyai hubungan dengan variabel-variabel laten tersebut.

\section{HASIL DAN PEMBAHASAN}

Hasil Analisis diskripsi Masing-masing variabel dalam penelitian ini seperti yang dapat dilihat pada Tabel 2. 
Tabel 2 Diskripsi Rata-rata dari Setiap Variabel Penelitian

\begin{tabular}{|l||c||c||}
\hline \multicolumn{1}{|c|}{ Variabel } & Nilai Rata-rata & Keterangan \\
\hline \hline Stress kerja & 4,34 & Selalu \\
\hline \hline Motivasi kerja & 4,64 & Selalu \\
\hline \hline Kompentensi guru & 4,56 & Selalu \\
\hline \hline Kinerja Guru & 4,47 & Selalu \\
\hline
\end{tabular}

Sumber: Data primer hasil olahan penelitian

Berdasarkan Tabel 2 menunjukkan bahwa dari 4 (empat) variabel dalam penelitian ini yang mendapatkan respons paling tinggi adalah motivasi kerja $(4,64)$ dalam kategori selalu, dan tertinggi kedua adalah variabel kompetensi guru (4.56) dalam kategori selalu, selanjutnya adalah variabel kinerja guru dengan penilain dalam kategori selalu (4.47), variabel stress kerja dalam kategori selalu (3.34).

Hasil analisis regression weights dan standardized regression weights seperti yang ditunjukkan pada Tabel 3

Tabel 3 Hasil Pengujian Hipotesis Model Persamaan Struktural

\begin{tabular}{|c|ll|r|r|r|l|}
\hline Hip & \multicolumn{2}{|c|}{ Pengaruh } & Koefisien & C.R. & Prob. & Keterangan \\
\hline $\mathrm{H}_{1}$ & Stres Kerja & $\rightarrow$ Kompetensi & -0.545 & - & 0,004 & Signifikan \\
\hline $\mathrm{H}_{2}$ & Motivasi & $\rightarrow \begin{array}{l}\text { Kompetensi } \\
\text { Guru }\end{array}$ & 1.282 & 1.998 & 0.046 & Signifikan \\
\hline $\mathrm{H}_{3}$ & Stres Kerja & $\rightarrow$ Kinerja Guru & -1.435 & -1.988 & 0,047 & Signifikan \\
\hline $\mathrm{H}_{4}$ & Motivasi kerja & $\rightarrow$ Kinerja Guru & 1.065 & 2.550 & 0,011 & Signifikan \\
\hline $\mathrm{H}_{5}$ & $\begin{array}{l}\text { Kompetensi } \\
\text { Guru }\end{array}$ & $\rightarrow$ Kinerja Guru & 1.100 & 2.038 & 0,042 & Signifikan \\
\hline
\end{tabular}

Sumber: Hasil Analisis SEM. Tahun 2015 
Berdasarkan Tabel 3 menunjukkan bahwa nilai-nilai yang dapat digunakan untuk menguji hipotesis dalam penelitian yaitu sebagai berikut 1. Nilai koefisien pengaruh Stres Kerja $\left(\mathrm{X}_{1}\right)$ terhadap Kompetensi Guru (Z) sebesar -0.545, artinya jika Stres Kerja naik maka kompetensi guru akan turun begitu juga sebaliknya jika stres kerja turun maka kompetensi guru akan naik. Nilai Critical Ratio sebesar -2.891 menunjukkan angka yang lebih kecil dengan nilai Z-score sebesar -1,96 atau nilai probability menunjukkan angka sebesar 0,004 maka dapat dikatakan bahwa pengaruh Stres Kerja $\left(\mathrm{X}_{1}\right)$ terhadap kompetensi guru (Z) adalah signifikan, jadi hipotesis ketujuh yang menyatakan Stres Kerja berpengaruh signifikan terhadap kompetensi guru diterima.

2. Nilai koefisien pengaruh Motivasi (X2) terhadap Kompetensi Guru (Z) sebesar 1.282, artinya jika Iklim Organisasi naik maka kinerja guru juga naik sebesar 1.282. Nilai Critical Ratio sebesar 1.998 menunjukkan angka yang lebih besar dengan nilai Z-score sebesar 1,96 atau nilai probability menunjukkan angka sebesar 0,000 maka dapat dikatakan bahwa pengaruh Motivasi (X2) terhadap Kompetensi Guru (Z) adalah signifikan, jadi hipotesis keenam yang menyatakan Motivasi berpengaruh signifikan terhadap Kompetensi Guru diterima.

3. Nilai koefisien pengaruh stres kerja $\left(\mathrm{X}_{1}\right)$ terhadap kinerja guru (Y) sebesar -1.435, artinya jika Stres Kerja naik maka kinerja guru akan turun begitu juga sebaliknya jika Stres Kerja turun maka kinerja guru akan naik. Nilai Critical Ratio sebesar -1.988 menunjukkan angka yang lebih kecil dengan nilai Z-score sebesar $-1,96$ atau nilai probability menunjukkan angka sebesar 0,047 maka dapat dikatakan bahwa pengaruh Stres Kerja $\left(\mathrm{X}_{1}\right)$ terhadap kinerja guru (Y) adalah signifikan, jadi hipotesis kesembilan yang menyatakan Stres Kerja berpengaruh signifikan terhadap kinerja guru diterima.

4. Nilai koefisien pengaruh motivasi kerja $\left(\mathrm{X}_{2}\right)$ terhadap kinerja guru $(\mathrm{Y})$ sebesar 1.065, artinya jika motivasi kerja naik maka kinerja guru akan naik. Nilai Critical Ratio sebesar 2.550 menunjukkan angka yang lebih besar dengan nilai $Z$-score sebesar 1,96 atau nilai probability menunjukkan angka sebesar 0,011 maka dapat dikatakan bahwa pengaruh motivasi kerja $\left(\mathrm{X}_{2}\right)$ terhadap kinerja guru $(\mathrm{Y})$ adalah 
signifikan, jadi hipotesis kesebelas yang menyatakan motivasi kerja berpengaruh signifikan terhadap kinerja guru diterima.

5. Nilai koefisien pengaruh kompetensi guru $(Z)$ terhadap kinerja guru (Y) sebesar 1.100, artinya jika kompetensi guru naik maka kinerja guru akan naik. Nilai Critical Ratio sebesar 2.038 menunjukkan angka yang lebih besar dengan nilai Z-score sebesar 1,96 atau nilai probability menunjukkan angka sebesar 0,042 maka dapat dikatakan bahwa pengaruh Kompetensi guru (Z) terhadap kinerja guru (Y) adalah signifikan, jadi hipotesis kesepuluh yang menyatakan kompetensi guru berpengaruh signifikan terhadap kinerja guru diterima.

\section{SIMPULAN}

Berdasarkan rumusan masalah, telaah pustaka, hasil penelitian dan pembahasan yang telah diuraikan, maka dari penelitian ini dapat ditarik beberapa simpulan antara lain sebagai berikut:

1. Stres kerja berpengaruh negatif dan signifikan terhadap kompetensi guru. Hasil penelitian mendukung teori Robbins (2005).

2. Motivasi berpengaruh dan signifikan terhadap kompetensi guru. Hasil penelitian mendukung teori Hoy dan Miskel (2001:430) serta sama dengan hasil penelitian Alwi Suddin (2009) dan I Dewa Putu Putra (2010) yang menyimpulkan bahwa Motivasi berpengaruh signifikan terhadap kompetensi guru.

3. Stres kerja berpengaruh negatif dan signifikan terhadap kinerja guru. Hasil penelitian mendukung teori Higgins dalam (Umar, 2010:259) serta sama dengan hasil penelitian Jerry Chandra (2012), Susilowati (2010), dan Setyo Edyatmo (2013) yang menyimpulkan bahwa stres kerja berpengaruh signifikan terhadap kinerja guru.

4. Motivasi kerja berpengaruh dan signifikan terhadap kinerja guru. Hasil penelitian mendukung teori Buhler (2004:191) serta sama dengan hasil penelitian Morales, Reche dan Torres (2008), Y. Sutomo (2006) yang menyimpulkan bahwa motivasi kerja berpengaruh signifikan terhadap kinerja guru.

5. Kompetensi guru berpengaruh dan signifikan terhadap kinerja guru. Hasil penelitian mendukung teori Mulyasa (2007) dan Simanjuntak (2007) serta sama dengan hasil penelitian I Nyoman Jigeh (2014), dan 
Erna Yuni Lestari (2013) yang menyimpulkan bahwa kompetensi guru berpengaruh signifikan terhadap kinerja guru.

\section{SARAN DAN REKOMENDASI}

\section{Saran Untuk Guru SMP Negeri di Sulawesi Barat}

Sesuai dengan hasil penelitian bahwa Kompetensi merupakan salah satu variabel yang memiliki pengaruh cukup penting terhadap Kinerja Guru SMP Negeri di Provinsi Sulawesi Barat maka setiap guru yang ada diharuskan untuk meningkatkan kompetensi yang dimiliki, misal dengan mengikuti berbagai workshop maupun seminar mengenai konsep pembelajaran. Dengan meningkatnya kompetensi yang dimiliki guru SMP Negeri di Provinsi Sulawesi Barat sehingga akan meningkatkan kinerja yang optimal.

\section{Saran Untuk Penentu Kebijakan}

Berdasarkan temuan bahwa faktor kompetensi yang dimiliki para guru merupakan hal yang sangat penting maka pengembangan kompetensi guru perlu di utamakan, karena sesuai dengan prinsip pendidikan yang hampir semuanya menyangkut Tri Dharma dalam pendidikan, untuk itu saran untuk pengambil kebijakan dalam hal ini Dinas Pendidikan atau pihak pemerintah yang terkait menginginkan kemajuan dari banyaknya SMP Negeri yang ada di Provinsi Sulawesi Barat maka hendaknya memberikan bimbingan dan pembinaan yang lebih di tekankan pada peningkatan kompetensi guru sehingga dapat berkontribusi terhadap pengembangan pendidikan di Provinsi Sulawesi Barat.

\section{Saran Untuk Peneliti Yang Akan Datang}

Penelitian tentang penggunaan variabel-variabel lain seperti kompensasi, pemberian insentif dan variabel lainnya dalam perilaku organisasi atau MSDM yang kemungkinan bisa meningkatkan kinerja Guru SMP Negeri di Provinsi Sulawesi Barat 


\section{DAFTAR PUSTAKA}

Arep dan Tanjung. 2003. Manajemen Motivasi. Jakarta : PT. Grasindo Hasibuan, Malayu SP. 2003. Organisasi dan Motivasi. Jakarta: PT Bumi Aksara.

Aksara. .2004. Dasar-Dasar Perbankan. Jakarta: Bumi 2005. Manajemen Sumber Daya Manusia. Jakarta: PT. Bumi Aksara.

Hoy, Wayne K. \& Miskel, Cecil G. 2000. Education Administration: Theory, Research, and Practice (6th ed., international edition). Singapure: Mc Graw-Hill Co.

Jigeh I Nyoman, 2014, Pengaruh Kompetensi Guru, Kepemimpinan dan Team Work terhadap Komitmen Sekolah dan Kinerja Guru SMK PGRI di Provinsi Bali (Disertasi). Surabaya: Universitas 17 Agustus Surabaya

Mulyasa E. 2004. Kurikulum Berbasis Kompetensi Konsep, Karakteristik, dan .2007. Standar Kompetensi dan Sertifikasi Guru (Cetakan ke dua). Bandung: PT. Remaja Rosdakarya. . 2008. Standar Kompetensi dan Sertifikasi Guru Guru (Cetakan ke tiga ). Bandung: PT. Remaja Rosdakarya.

Muchlas Makmuri. 2008. Perilaku Organisasi. Yogyakarta: Gajah Mada University Press.

Putra I Dewa Putu, 2010, Pengaruh Karakteristik Individu, Kompetensi, Disiplin Kerja, Linglkungan Kerja dan Kepemimpinan Diri Terhadap Kepuasan Kerja dan Kinerja Guru SMA RSBI di Provinsi Bali (Disertasi). Surabaya: Universitas 17 Agustus Surabaya

Riduwan. 2013. Metode \& Teknik Menyusun Proposal Penelitian. Bandung : Alfabeta

Robbin, S. P. \& Timothy A. Judge. 2008. Perilaku Organisasi, Alih Bahasa oleh Hadyana Pujaatmaka. Jakarta: Salemba Empat. 
Rusman. 2012. Model-Model Pembelajaran Mengembangkan Profesionalisme Guru. (Ed. Kedua). Jakarta: PT. Grapindo Persada.

Sardiman AM. 2012. Interaksi \& Motivasi Belajar Mengajar. Jakarta: Rajawali Pers.

Sugiyono. 2013. Metode Penelitian Pendidikan Pendekatan Kuantitatif, Kualitatif, dan R\&D. Bandung : Alfabeta.

Supardi. 2013. Kinerja Guru. Jakarta: PT. Rajawali Grafindo Persada. Susilowati. 2010. Pengaruh Stres Kerja terhadap Motivasi dan Dampaknya Pada Kinerja Karyawan Bagian Marketing PT. Junger Farma Distributor di Surabaya. Surabaya : Universitas Pembangunan Nasional "Veteran" Jawa timur

Uno Hamzah B. 2007. Teori Motivasi dan Pengukurannya. Jakarta. PT. Bumi Aksara. 